\title{
Enhanced Artificial Coronary Circulation System Algorithm for Truss Optimization with Multiple Natural Frequency Constraints
}

\author{
Ali Kaveh ${ }^{1 *}$, Mohsen Kooshkbaghi² \\ ${ }^{1}$ Department of Civil Engineering, \\ Iran University of Science and Technology, \\ Narmak, Postal Code 1684613114, Tehran, Iran \\ 2 Department of Civil Engineering, \\ Science and Research Branch, \\ Islamic Azad University, Tehran, Iran \\ *Corresponding author, e-mail: alikaveh@iust.ac.ir
}

Received: 06 December 2018, Accepted: 07 January 2019, Published online: 28 January 2019

\begin{abstract}
In this paper, an enhanced artificial coronary circulation system (EACCS) algorithm is applied to structural optimization with continuous design variables and frequency constraints. The standard algorithm, artificial coronary circulation system (ACCS), is inspired biologically as a non-gradient algorithm and mimics the growth of coronary tree of heart circulation system. Designs generated by the EACCS algorithm are compared with other popular evolutionary optimization methods, the objective function being the total weight of the structures.

Truss optimization with frequency constraints has attracted substantial attention to improve the dynamic performance of structures. This kind of problems is believed to represent nonlinear and non-convex search spaces with several local optima. These problems are also suitable for examining the capabilities of the new algorithms. Here, ACCS is enhanced (EACCS) and employed for size and shape optimization of truss structures and six truss design problems are utilized for evaluating and validating of the EACCS. This algorithm uses a fitness-based weighted mean in the bifurcation phase and runner phase of the optimization process. The numerical results demonstrate successful performance, efficiency and robustness of the new method and its competitive performance to some other well-known meta-heuristics in structural optimization.
\end{abstract}

Keywords

meta-heuristic, ACCS algorithm, enhanced ACCS algorithm, structural optimization, shape and size optimization, frequency constraints

\section{Introduction}

Optimal design of truss structures subjected to dynamic behavior has been a challenging area of study and it is an active research area. Optimal truss design subjected to frequency bounds is a valuable tool for improving the dynamic behavior of the truss [1-5]. Natural frequencies of a truss should be enforced to avoid resonance with an external excitation. In addition, engineering compositions should be as light as possible. On the other hand, mass minimization conflicts with frequency bounds and increases the complexity of the problem $[6,8,9]$. As such, an expeditious optimization method is required to design the trusses susceptible to fundamental frequency constraints, and continuous effort is put by researchers in this aspect $[7,10]$.
Size, shape, and topology optimizations are three main kinds of truss optimization. In size optimization, the final goal is to acquire the best bar sections, whereas shape optimization insures the best nodal positions of predefined nodes of the truss structure. The effect of shape and sizing on objective function and constraints are in conflict. Hence, simultaneous shape and sizing optimization with natural frequency bounds adds further complexity and often leads to fluctuations [11]. Several researchers have been using different optimization algorithms, yet this research area has not yet been fully investigated. In recent years, many optimization techniques have been studied in this application area [12-17]. 
Structural optimization can be categorized into two classes: discrete structural optimization and continuum structural optimization. Discrete structural optimization is also best-known as truss optimization, having connectivity of finite dimension parameters as variables (naturally discrete parameter system) and continuum structural optimization have field as a variable (discretized parameter system) [18-20].

This paper suggests the application of the recently developed optimization algorithm, so-called the Artificial Coronary Circulation System (ACCS) [21], for optimum design of truss structures with frequency constraints. Moreover, an enhanced version of the ACCS, called EACCS, is applied to the problem in hand. In this method, the solution candidates are considered as capillaries leaders that growth in direction best position for enhancing the dissemination system. Improving heart circulation system is achieved from current population and historically best position in order to have a suitable balance between exploration and exploitation.

In order to evaluate the performance of the ACCS, six truss structures are optimized for minimum weight with the design variables being considered as the cross-sectional areas of the members and/or the coordinates of some nodes. The truss examples have 10, 72, 120, 200, 37 and 52 members, respectively. The numerical results indicate that the planned algorithm is rather competitive with other state-of-the-art metaheuristic methods.

This study has been organized as follows: In Sect. 2, the mathematical formulation of the structural optimization with frequency constraints is stated. The enhanced algorithm EACCS is presented after a brief overview of the standard ACCS in Sect. 3. Six structural design examples are studied in Sect. 4, and some concluding remarks are eventually provided in Sect. 5 .

\section{Statement of the optimization problem}

In a frequency constraint truss shape and size optimization problem, the goal is to minimize the weight of the structure while satisfying some constraints on natural frequencies. The design variables are the cross-sectional areas of the members and/or the coordinates of some nodes. The topology of the structure is not expected to be changed and thus the connectivity of the structure is predefined and kept unaltered during the optimization process. For each one of the design variables should be chosen from a permissible range. The optimization problem can be stated mathematically as follows:
Find $X=\left[x_{1}, x_{2}, \ldots, x_{n}\right]$,

To minimizes $\quad G(X)=f(X) \cdot\left(1+f_{\text {penalty }}(X)\right)$

Subjected to $\begin{cases}\omega_{j} \leq \omega_{j}^{*} & \text { for some natural frequencies } j \\ \omega_{k} \geq \omega_{k}^{*} & \text { for some natural frequencies } k\end{cases}$

$x_{\min } \leq x_{i} \leq x_{\max }$,

where $X$ is the vector of the design variables, including both nodal coordinates and cross-sectional areas. Here, $n$ is the number of variables which is naturally affected by the element grouping scheme which in turn is chosen considering the symmetry and practice requirements. $G(X)$ is the merit function; $f(X)$ is the cost function, which has been taken as the weight of the structure in a weight optimization problem; $f_{\text {penalty }}(X)$ is the penalty function that is used to make the problem unconstrained. When all of the constraints are contented, the penalty function value is equal to unity; $\omega_{j}$ is the $j$ th natural frequency of the structure and $\omega_{j}^{*}$ is its upper bound. $\omega_{k}$ is the $k$ th natural frequency of the structure and $\omega_{k}{ }^{*}$ is its lower bound; $x_{\min }$ and $x_{\max }$ are the lower and upper bounds of the design variable $x_{i}$, respectively. The cost function is expressed as:

$f(X)=\sum_{i=1}^{N_{\text {var }}} \rho_{i} L_{i} A_{i}$,

where $\rho_{i}$ is the material density of member $i ; L_{i}$ is the length of member $i$; and $A_{i}$ is the cross-sectional area of the $i$ th member.

The penalty function is defined as:

$$
f_{\text {penalty }}(X)=\left(1+\varepsilon_{1} \cdot c\right)^{\varepsilon_{2}} \quad c=\sum_{i=1}^{q} c_{i},
$$

where $q$ is the number of frequency constraints. If the $i$ th constraint is satisfied, $c_{i}$ will be taken as zero, otherwise it will be considered as:

$$
c_{i}=\left\{\begin{array}{cc}
0 & \text { if the ith constraint is satisfied } \\
1-\frac{\omega_{i}}{\omega_{i}^{*}} \mid & \text { else }
\end{array}\right.
$$

The parameters and are selected considering the exploration and the exploitation rate of the search space. In this study is taken as unity, and starts from 1.5 and linearly increases to 6 in all the test examples. These values penalize the unfeasible solutions more severely as the optimization procedure proceeds. As a result, in the primal stages, the agents are autonomous to explore the search space, but at the end they tend to choose solutions without violation. 


\section{Artificial Coronary Circulation System (ACCS) Optimization}

ACCS is a coronary tree growth process inspired algorithm, proposed by Kaveh and Kooshkbaghi [21]. This algorithm is based on coronary circulation of the heart muscle. The ACCS algorithm consists of two basic modes of the growing coronary tree: (i) produce stem-crown (known as bifurcation phase), and (ii) growing with the other capillaries (known as pruning phase). In this optimization algorithm an initial group of capillaries is considered as population and different main arteries are considered as different design variables of the optimization problem and a capillary leader's result is analogous to the "fitness value" of the optimization problem. In this algorithm, any branches of coronary tree is considered as a new solution and the total cost of the tree at any end is considered as the cost of the object function at any solution. With these values, the Coronary Growth Factor (CGF) is calculated for any solution. This result is analogous to the fitness value of the optimization problem. Also, the best solution in the entire population is considered as the stem, and the best solution is the minimum value of the CGF.

The process of the ACCS is divided into two main parts, 'Bifurcation phase' and 'Pruning phase'. The ACCS procedure can be briefly outlined as follows:

\subsection{Bifurcation and Pruning phase (Global Search)}

During this phase, a capillary leader tries to improve the CGF of the center of the suggested capillary leaders by the end of stem. Thus, at any iteration $t$, it is assumed that there are $N_{v a r}$ number of main arteries (i.e. design variables, $j=1,2, \ldots, N_{v a r}$ ), Npop is the number of capillary leaders (i.e. population size, $i=1,2, \ldots, N_{p o p}$ ) and $X_{c}^{t, j}$ is the mean of all the $j$ th subjects of capillary leaders in a current capillaries population. However, the best capillary leader (CL) identified is considered by the algorithm as the stem. Thus, the CGF of the CLs are mathematically formulated as follows:

$$
\begin{aligned}
& C G F_{i}^{t}=\frac{1 / \text { fit }_{i}}{\sum 1 / f i t_{i}}, \quad i=1,2, \ldots, N_{p o p}, \\
& C G F_{c}^{t}=\frac{1 / f i t_{c}}{\sum 1 / f i t_{i}} \\
& f i t_{c}=\operatorname{mean}\left(f_{i t}\right) .
\end{aligned}
$$

Then the existing solution is updated in the bifurcation phase according to the following expression:

$$
\begin{aligned}
& X_{i, j}^{t+1}=X_{i, j}^{t}+\operatorname{dir} . B_{f} \cdot\left(X_{c, j}^{t}-\operatorname{rand} . X_{i, j}^{t}\right) \\
& i=1, \&, N_{p o p}, \quad j=1, \&, N_{v a r}, \\
& \left\{\begin{array}{ccc}
\operatorname{dir}=-1 & \text { if } & C G F_{c}^{t}<C G F_{i}^{t}, \\
\operatorname{dir}=+1 & \text { else }
\end{array}\right. \\
& X_{c, j}=\operatorname{mean}\left(X_{j}^{t}\right) \quad j=1, \ldots, N_{\text {var }},
\end{aligned}
$$

where $X_{i, j}^{t+1}$ indicates the new position value of the $j$ th variable for the ith CL; and "dir" denotes the growth direction; and "rand" is a random number uniformly distributed in the range of $(0,1) ; B_{f}$ is the bifurcation factor and it determines the growth step and is equal to $C G F_{i}$; and $X_{i, j}^{t}$ indicates the old position value of the $j$ th variable for the $i$ th CL.

\subsection{Runner and Pruning phase (Local Search)}

As mentioned in the previous steps, the best CLs are considered as the main arteries leaders and are converted to stems and the coronary tree grows. In this stage, all the new CLs grow at the end of the stems and create new CLs. Also, the CLs growth is based on the coronary growth factor (CGF) of the arteries leader along the coronary arteries tree. Therefore, an exponent factor is defined as follow:

$X_{i, j}^{t+1}=X_{i, j}^{t}+\alpha . r a n d .\left(X_{b, j}^{t}-X_{w, j}^{t}\right)$,

where $X_{i, j}^{t+1}$ determines the new position value of the $j$ th variable for the $i$ th $\mathrm{CL}$; and $X_{i, j}^{t}$ determines the old position value of the $j$ th variable for the $i$ th $\mathrm{CL} ; \alpha$ is angiogenesis index and it is a decreasing function of time, which controls the pumping power of the heart. It is initialized to 1 at the beginning of the algorithm and is exponentially decreased to about 0.6 as the iterations elapse; and rand is a random numbers uniformly distributed in the range of $(0,1)$; and $X_{b, j}^{t}$ and $X_{w, j}^{t}$ are the best and the worst CLs of the last (old) population which refer to the best arteries leader and the worst arteries leader. According to the above equations, each CL searches the space for the new position for growth as the capillaries.

Therefore, after each above mechanism, the best and worst CLs are found and the old values are updated. Also any component of the solution vector violating the variable boundaries can be regenerated from the Heart Memory (HM). Then, a memory is considered which saves the best CL vectors and their related coronary growth factor (CGF) values. So, the Heart Memory Considering Rate (HMCR) varying between 0 and 1 sets the rate of choosing a value 
in the new values from the historic values stored in the HM. In this study, the size of the HM (i.e. HMS) is taken as 5 and the HMCR is considered as 0.95 .

\subsection{Enhanced Artificial Coronary Circulation System}

The purpose of this section is to introduce an improved version of the standard ACCS, Enhanced Artificial Coronary Circulation System (EACCS) optimization modifies the ACCS to get better solutions. The ACCS and EACCS use a heart memory (HM) for saving some of the best solutions and updating them in each iteration. The HM enables the ACCS and EACCS to have a stronger exploitation and better convergence. Furthermore, using a mechanism to change some components of capillaries leaders helps the algorithm to escape from local optima. The EACCS procedure is similar to that of ACCS, where only one step is added to its procedure:

\section{Step 1: Initialization}

The initial positions for CLs are determined randomly in the search space as:

$X_{i}^{0}=X_{\min }+\operatorname{rand} .\left(X_{\max }-X_{\min }\right), \quad i=1, \ldots, n_{\text {pop }}$,

where $X_{i, j}^{0}$ is the initial solution vector of the $i$ th CL. Here, $X_{\min }$ and $X_{\max }$ are the bounds of design variables; rand is a random vector with each component being in the interval $[0,1] ; N_{p o p}$ is the number of the population of CLs.

Step 2: Defining Coronary Growth Factor (CGF)

The value of CGF for each CL is evaluated according to Eqs. (6 and 7).

Step 3: Storing. Heart memory (HM) is utilized to save several historically best capillary leaders (CL vectors) and their related CGF and the objective function values. Solution vectors that are saved in the HM are added to the population, and the same number of current worst CLs is deleted. Finally, CLs are sorted according to their objective function values in an increasing order. Using this mechanism can improve the algorithm performance without increasing the computational cost.

Step 4: Bifurcation and Pruning phase and Jump out: To improve the exploration capability of the standard ACCS and to prevent premature convergence, a stochastic approach is used in EACCS. A parameter like Pro that is a number within $(0,1)$ is introduced and specified whether a component of each CL must be changed or not. The value of Pro is evaluated according to Eq. (14).

$$
\boldsymbol{P r o}=\omega_{\min }+\left(\frac{i t r}{i t r_{\max }}\left(\omega_{\max }-\omega_{\min }\right)\right)
$$

In this paper, the value of Pro is equal to 0.1 at the beginning of the search to emphasize the exploration, and then it is linearly increased to 0.3 at the end to encourage the exploitation.

For each CL, Pro is compared with $\boldsymbol{R a n d}_{i}\left(i=1, \ldots, N_{p o p}\right)$, which is a random number uniformly distributed within $(0,1)$. Thus, the design variable of the $i$ th $C L$ value is regenerated by

$$
\begin{aligned}
& \left\{\begin{array}{l}
\text { Eqs.(9) and }(10) \text { and }(16) \\
X_{i, j}=X_{\min , j}+\text { rand. }\left(X_{\max , j}-X_{\min , j}\right)
\end{array} \quad \begin{array}{c}
\text { if } \text { Rand }_{i}<\text { Pro } \\
\text { else }
\end{array}\right. \\
& X_{c, j}=\frac{\sum_{i=1}^{n_{p o p}} \frac{X_{j}}{f i t_{i}}}{\sum_{i=1}^{n_{\text {pop }}} \frac{1}{f i t_{i}}} \quad j=1, \ldots, n_{\text {var }},
\end{aligned}
$$

where $X_{i, j}=j$ th design variable of the $i$ th $\mathrm{CL} ; X_{\min , j}$ and $X_{\text {max }, j}$ are minimum and maximum limits of the $j$ th design variable. Then, the CLs are updated and sorted according to their objective function values.

Step 5: Runner and Pruning phase. Updating CLs and the new position of each CL are performed by Eq. (12). The updated CLs are sorted according to their objective function values.

Step 6: Updating Heart Memory. Keeping the best CLs in each iteration.

Step 7: Terminating condition check. The process of optimization is terminated after the predefined maximum evaluation number. Otherwise, the process is continued by going to Step 2.

A flowchart of the EACCS algorithm is shown in Fig. 1.

\section{Numerical examples}

In this section, six most often used numerical examples are studied by the proposed methods. These examples consist of four truss structures for size optimization and two structures for shape and size optimization. The performance of the standard ACCS and EACCS are examined through six standard design optimization problems.

These examples include some well-known planar and space trusses. The population number of the CLs or agents for these examples is taken as 20 for both methods. Also, for all these examples the maximum number of iterations is considered as 200. Material properties, cross-sectional area bounds, and frequency constraints are provided in Table 1. 


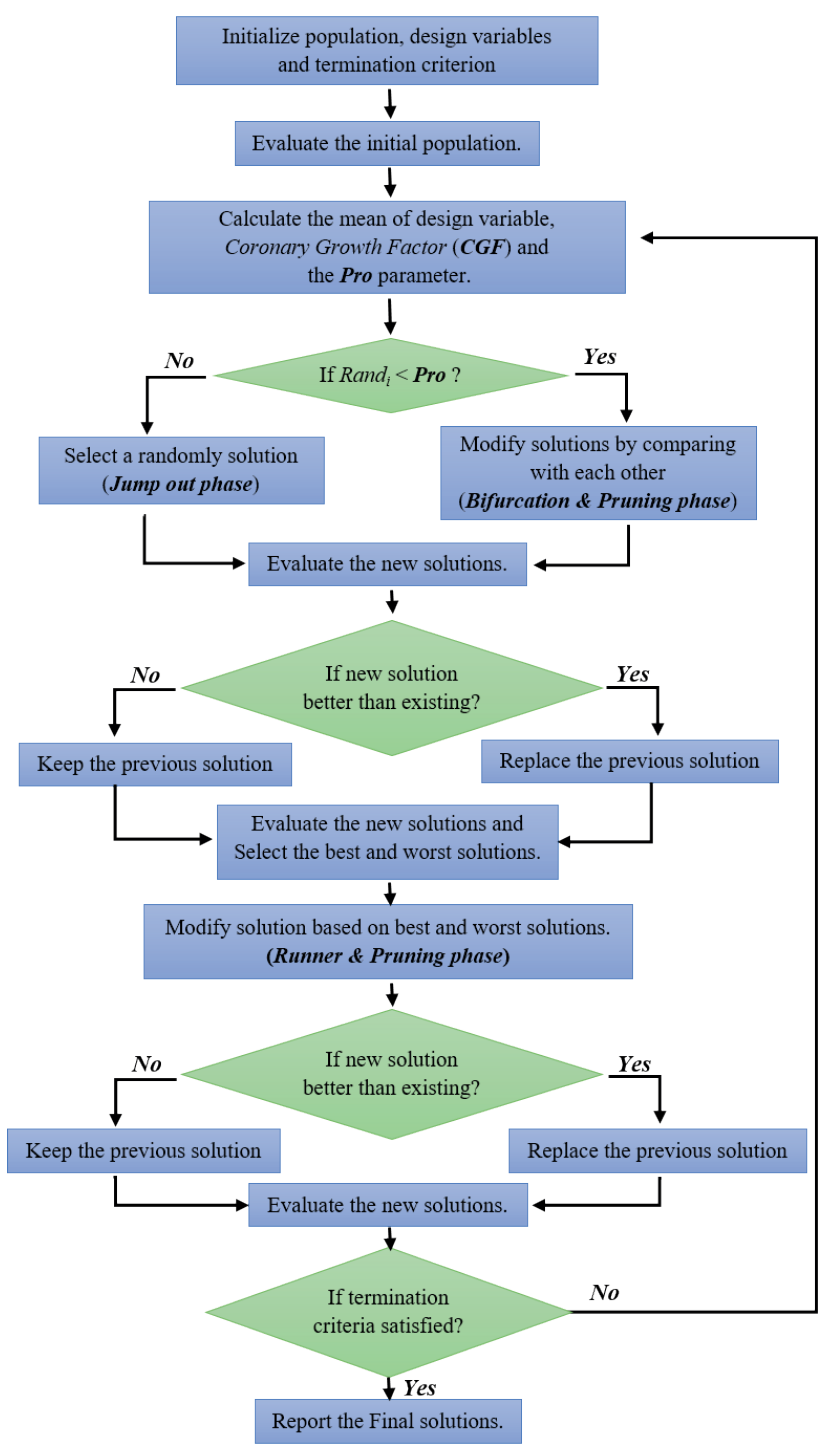

Fig. 1 A Flowchart Of The EACCS Algorithm

For all examples, 10 independent optimization runs are executed as meta-heuristic algorithms have stochastic nature and their performance may be sensitive to initial population. The frequency constraints are handled using the well-known penalty approach.

Subsequently, statistical results are presented in terms of the best weight and the corresponding number of FE analyses, the mean weight and standard deviation. Only design variable values achieved from the best run are reported for comparison with those given by other optimization approaches to illustrate the accuracy and robustness of the proposed algorithm. Also, the ACCS and EACCS algorithms and the direct stiffness method for the analysis of truss structures are coded in MATLAB software. The example results are based on a Laptop with a CPU 2.4 $\mathrm{GHz}$, and 6.0 GB of RAM. Also, the operation system is Windows 10 and the version of the MATLAB is R2016a.
Table 1 Material properties, cross-sectional area bounds, and frequency constraints for different problems.

\begin{tabular}{|c|c|c|c|c|}
\hline \multirow[b]{2}{*}{ Problem } & \multicolumn{4}{|c|}{ Property (unit) } \\
\hline & $\begin{array}{l}\text { Young's } \\
\text { modulus } \\
\left(\mathrm{N} / \mathrm{m}^{2}\right)\end{array}$ & $\begin{array}{l}\text { Material } \\
\text { density } \\
\left(\mathrm{kg} / \mathrm{m}^{3}\right)\end{array}$ & $\begin{array}{l}\text { Cross-sectional } \\
\text { area bounds } \\
\left(\mathrm{cm}^{2}\right)\end{array}$ & $\begin{array}{c}\text { Frequency } \\
\text { constraints } \\
(\mathrm{Hz})\end{array}$ \\
\hline $\begin{array}{l}\text { 10-bar } \\
\text { planar } \\
\text { truss }\end{array}$ & $\begin{array}{c}6.89 \times \\
10^{10}\end{array}$ & 2770 & $0.645 \times 10^{-4} \leq \mathrm{A}_{\mathrm{i}}$ & $\begin{array}{c}\mathrm{f}_{1} \geq 7 \\
\mathrm{f}_{2} \geq 15 \\
\mathrm{f}_{3} \geq 20\end{array}$ \\
\hline $\begin{array}{l}\text { 72-bar } \\
\text { space } \\
\text { truss }\end{array}$ & $\begin{array}{c}6.89 \times \\
10^{10}\end{array}$ & 2770 & $0.645 \times 10^{-4} \leq \mathrm{A}_{\mathrm{i}}$ & $\begin{array}{l}f_{1}=4 \\
f_{2} \geq 6\end{array}$ \\
\hline $\begin{array}{l}\text { 120-bar } \\
\text { dome } \\
\text { truss }\end{array}$ & $2.1 \times 10^{11}$ & 7971.81 & $\begin{array}{c}0.0001 \leq \mathrm{A}_{\mathrm{i}} \leq \\
0.01293\end{array}$ & $\begin{array}{c}\mathrm{f}_{1} \geq 9 \\
\mathrm{f}_{2} \geq 11\end{array}$ \\
\hline $\begin{array}{l}\text { 200-bar } \\
\text { planar } \\
\text { truss }\end{array}$ & $2.1 \times 10^{11}$ & 7860 & $0.1 \times 10-4 \leq \mathrm{A}_{\mathrm{i}}$ & $\begin{array}{l}\mathrm{f}_{1} \geq 5 \\
\mathrm{f}_{2} \geq 10 \\
\mathrm{f}_{3} \geq 15\end{array}$ \\
\hline $\begin{array}{l}\text { 37-bar } \\
\text { planar } \\
\text { truss }\end{array}$ & $2.1 \times 10^{11}$ & 7800 & $0.1 \times 10-4 \leq \mathrm{A}_{\mathrm{i}}$ & $\begin{array}{l}\mathrm{f}_{1} \geq 20 \\
\mathrm{f}_{2} \geq 40 \\
\mathrm{f}_{3} \geq 60\end{array}$ \\
\hline $\begin{array}{l}\text { 52-bar } \\
\text { dome } \\
\text { truss }\end{array}$ & $2.1 \times 10^{11}$ & 7800 & $\begin{array}{c}0.0001 \leq \mathrm{A}_{\mathrm{i}} \leq \\
0.001\end{array}$ & $\begin{array}{l}\mathrm{f}_{1} \leq 15.9155 \\
\mathrm{f}_{2} \geq 28.6479\end{array}$ \\
\hline
\end{tabular}

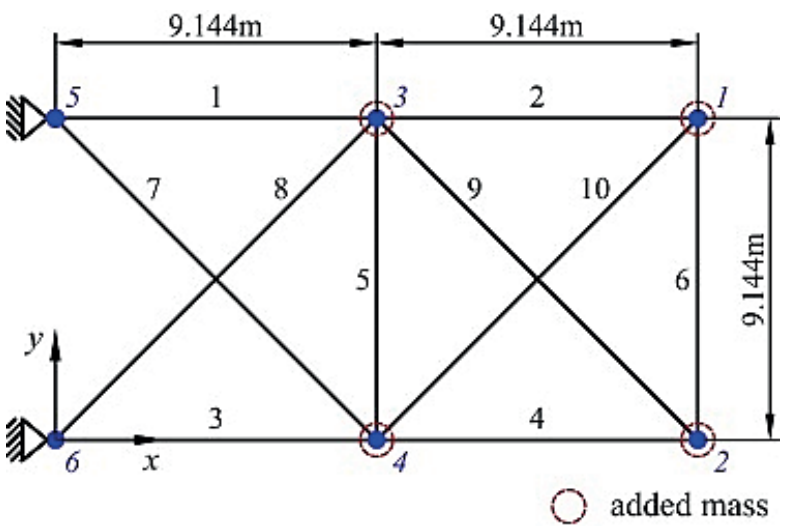

Fig. 2 Schematic of a 10-bar planar truss structure

\subsection{Size optimization}

\subsubsection{The 10-bar plane truss}

Schematic of the 10-bar plane truss, displayed in Fig. 2, is the first test problem. The cross-sectional area of each of the members is an independent variable. Here, cross-sectional areas of all bars are treated as continuous design variables. Four nonstructural masses of $454 \mathrm{~kg}$ are assigned with four free nodes as indicated in the same figure. Besides, as one of the benchmark problems, this structure has been studied by other researchers that are listed in the pursuing literature [4-6, 8-10, 17, 22-24].

Table 2 shows a comparison of the optimal results obtained by the present algorithms with different approaches. The optimal weight accomplished by the proposed EACCS is 
Table 2 Comparison of optimal results of the 10-bar planar truss obtained by different algorithms

\begin{tabular}{|c|c|c|c|c|c|c|}
\hline \multirow{2}{*}{ Design variable $\left(\mathrm{cm}_{2}\right)$} & \multirow{2}{*}{ GA [22] } & \multirow{2}{*}{ PSO [5] } & \multirow{2}{*}{ CSS [8] } & \multirow{2}{*}{ FA [10] } & \multicolumn{2}{|c|}{ This work } \\
\hline & & & & & ACCS & EACCS \\
\hline $\mathrm{A}_{1}$ & 42.230 & 37.712 & 38.811 & 36.198 & 35.5557 & 35.0354 \\
\hline $\mathrm{A}_{2}$ & 18.555 & 09.959 & 09.0307 & 14.030 & 15.1448 & 15.0132 \\
\hline $\mathrm{A}_{3}$ & 38.851 & 40.265 & 37.099 & 34.754 & 35.4367 & 35.4505 \\
\hline $\mathrm{A}_{4}$ & 11.222 & 16.788 & 18.479 & 14.900 & 14.8101 & 15.0603 \\
\hline $\mathrm{A}_{5}$ & 04.783 & 11.576 & 04.479 & 00.654 & 0.651 & 0.6475 \\
\hline $\mathrm{A}_{6}$ & 04.451 & 03.955 & 04.205 & 04.672 & 4.5225 & 4.5224 \\
\hline $\mathrm{A}_{7}$ & 21.049 & 25.308 & 20.842 & 23.467 & 23.9125 & 23.4493 \\
\hline $\mathrm{A}_{8}$ & 20.949 & 21.613 & 23.023 & 25.508 & 23.1290 & 23.4182 \\
\hline $\mathrm{A}_{9}$ & 10.257 & 11.576 & 13.763 & 12.707 & 12.0245 & 12.1051 \\
\hline $\mathrm{A}_{10}$ & 14.342 & 11.186 & 11.414 & 12.351 & 12.3559 & 12.7158 \\
\hline Best weight (kg) & 542.750 & 537.980 & 531.950 & 531.280 & 524.6371 & 524.6001 \\
\hline Average weight (kg) & 552.447 & 540.890 & 536.390 & 535.070 & 525.4842 & 525.0068 \\
\hline Standard deviation & 04.864 & 06.840 & 03.320 & 03.640 & 2.8756 & 0.3030 \\
\hline No. of analyses & 13,777 & 20,000 & 4,000 & 5,000 & 8,000 & 8,000 \\
\hline
\end{tabular}

Note: GA = Genetic Algorithm; PSO = particle swarm optimization; CSS = charged system search; FA = firefly algorithm; CPA= Cyclical Parthenogenesis Algorithm; ACCS = Artificial Coronary Circulation System; N/A = not available.

Table 3 Natural frequencies $(\mathrm{Hz})$ of the optimized designs for the 10-bar planar truss

\begin{tabular}{|c|c|c|c|c|c|c|}
\hline \multirow{2}{*}{ Frequency no. } & \multirow{2}{*}{ GA [22] } & \multirow{2}{*}{ PSO [5] } & \multirow{2}{*}{ CSS [8] } & \multirow{2}{*}{ FA [10] } & \multicolumn{2}{|c|}{ This work } \\
\hline & & & & & ACCS & EACCS \\
\hline 1 & 07.008 & 07.000 & 07.000 & 07.0002 & 07.0000 & 07.0000 \\
\hline 2 & 18.148 & 17.786 & 17.442 & 16.1640 & 16.2358 & 16.2094 \\
\hline 3 & 20.000 & 20.000 & 20.031 & 20.0029 & 20.0000 & 20.0000 \\
\hline 4 & 20.508 & 20.063 & 20.208 & 20.0221 & 20.0018 & 20.0001 \\
\hline 5 & 27.797 & 27.776 & 28.261 & 28.5428 & 28.3855 & 28.4486 \\
\hline 6 & 31.281 & 30.939 & 31.139 & 28.9220 & 28.8872 & 29.0761 \\
\hline 7 & 48.304 & 47.297 & 47.704 & 48.3538 & 48.8085 & 48.7494 \\
\hline 8 & 53.306 & 52.286 & 52.420 & 50.8004 & 51.2694 & 51.2833 \\
\hline
\end{tabular}

better than other methods. Table 3 represents the first eight optimal natural frequencies obtained by the present work and different researches. All the frequencies strictly satisfy the allowable constraints and no constraint is violated.

The best and average convergence curves for these algorithms are illustrated in Fig. 3. This algorithm rapidly discovers the optimal solution with only 5860 analyses, while the others algorithms require a larger number of analyses for the convergence. Also, the EACCS has minimum standard deviation among the presented solutions.

\subsubsection{The 72-bar space truss}

The second example aims to optimize a 72-bar space truss whose geometry and finite element model are depicted in Fig. 4. The values of the cross-sectional area, minimum weight, and statistical information of the solution obtained by the standard ACCS, EACCS, and some other previous studies reported in the literature are presented in Table 4. Four non-structural masses of $2270 \mathrm{~kg}$ are attached to four upper nodes. This is also a benchmark problem that has previously been examined by a variety of researchers such as Refs. [6, 8, 9, 17].

Optimal results obtained by the present methods with different algorithms are provided in Table 4 for comparison. As it can be observed, the EACCS results in the smallest weight in comparison to the other algorithms. Table 5 reports the natural frequencies of the optimized structures; clearly, none of the frequency constraints are violated. The weight convergence histories obtained using both algorithms for this example are illustrated in Fig. 5. It is found that the EACCS needs far fewer number of FE analyses to gain the optimal solution compared to the other algorithms. 
Table 4 Optimal cross-sectional areas for the 72-bar space truss $\left(\mathrm{cm}^{2}\right)$

\begin{tabular}{|c|c|c|c|c|c|c|c|c|}
\hline \multirow{2}{*}{ Group No. } & \multirow{2}{*}{ Elements } & \multirow{2}{*}{ PSO [5] } & \multirow{2}{*}{ HS [10] } & \multirow{2}{*}{ CSS [8] } & \multirow{2}{*}{ FA [10] } & \multirow{2}{*}{ CPA [6] } & \multicolumn{2}{|c|}{ This work } \\
\hline & & & & & & & ACCS & EACCS \\
\hline $\mathrm{G}_{1}$ & $1-4$ & 2.987 & 3.6803 & 2.528 & 3.341 & 3.329 & 4.1886 & 3.7122 \\
\hline $\mathrm{G}_{2}$ & $5-12$ & 7.849 & 7.6808 & 8.704 & 7.759 & 7.841 & 7.9958 & 7.7434 \\
\hline $\mathrm{G}_{3}$ & $13-16$ & 0.645 & 0.6450 & 0.645 & 0.645 & 0.645 & 0.6813 & 0.6468 \\
\hline $\mathrm{G}_{4}$ & $17-18$ & 0.645 & 0.6450 & 0.645 & 0.645 & 0.645 & 0.7430 & 0.697 \\
\hline $\mathrm{G}_{5}$ & $19-22$ & 8.765 & 9.4955 & 8.283 & 9.020 & 8.416 & 6.4211 & 8.2884 \\
\hline $\mathrm{G}_{6}$ & $23-30$ & 8.153 & 8.2870 & 7.888 & 8.257 & 8.160 & 7.6720 & 8.2141 \\
\hline $\mathrm{G}_{7}$ & $31-34$ & 0.645 & 0.6450 & 0.645 & 0.645 & 0.645 & 0.7656 & 0.6658 \\
\hline $\mathrm{G}_{8}$ & $35-36$ & 0.645 & 0.6461 & 0.645 & 0.645 & 0.645 & 0.7014 & 0.6743 \\
\hline $\mathrm{G}_{9}$ & $37-40$ & 13.450 & 11.4510 & 14.666 & 12.045 & 13.078 & 14.0034 & 12.15 \\
\hline $\mathrm{G}_{10}$ & $41-48$ & 8.073 & 7.8990 & 6.793 & 8.040 & 8.043 & 8.1338 & 7.87 \\
\hline $\mathrm{G}_{11}$ & $49-52$ & 0.645 & 0.6473 & 0.645 & 0.645 & 0.645 & 0.6612 & 0.7058 \\
\hline $\mathrm{G}_{12}$ & $53-54$ & 0.645 & 0.6450 & 0.645 & 0.645 & 0.645 & 0.6810 & 0.6526 \\
\hline $\mathrm{G}_{13}$ & $55-58$ & 16.684 & 17.4060 & 16.464 & 17.380 & 16.943 & 17.1666 & 17.0882 \\
\hline $\mathrm{G}_{14}$ & $59-66$ & 8.159 & 8.2736 & 8.809 & 8.056 & 8.143 & 7.9807 & 7.9472 \\
\hline $\mathrm{G}_{15}$ & $67-70$ & 0.645 & 0.6450 & 0.645 & 0.645 & 0.647 & 0.7097 & 0.645 \\
\hline $\mathrm{G}_{16}$ & $71-72$ & 0.645 & 0.6450 & 0.645 & 0.645 & 0.653 & 0.6532 & 0.7462 \\
\hline Best weight (kg) & 328.823 & 328.334 & 328.814 & 327.690 & 328.490 & 326.7081 & 325.1956 & \\
\hline Average weight $(\mathrm{kg})$ & - & 332.640 & 337.700 & 329.890 & 330.910 & 327.9035 & 326.3036 & \\
\hline Standard deviation & - & 2.390 & 5.420 & 2.590 & 1.840 & 1.3413 & 0.650 & \\
\hline No. of analyses & - & 50,000 & 4,000 & 10,000 & 12,800 & 12,000 & 12,000 & \\
\hline
\end{tabular}

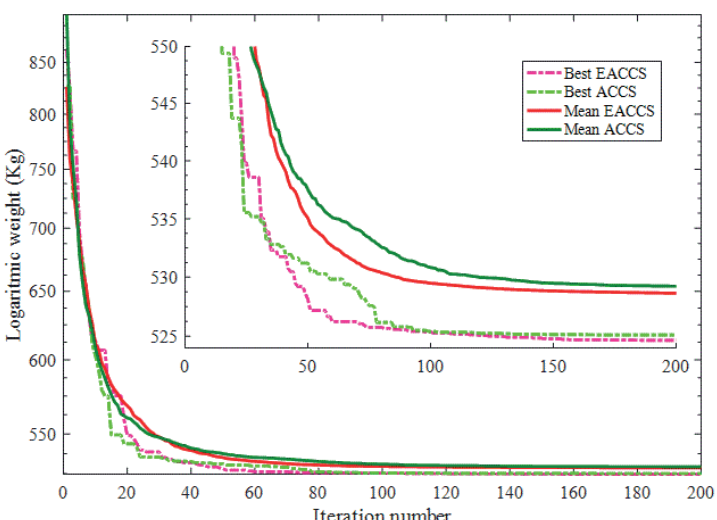

Fig. 3 The weight convergence histories of the 10-bar planar truss obtained using the ACCS and EACCS

\subsubsection{The 120-bar dome truss}

The third example aims to optimize a 120-bar dome truss as shown in Fig. 6. Non-structural masses are attached to all the free nodes as follows: $3,000 \mathrm{~kg}$ at Node 1, $500 \mathrm{~kg}$ at Nodes 2-13, and $100 \mathrm{~kg}$ at the remaining nodes. The symmetry of the structure about the $\mathrm{x}$-axis and $\mathrm{y}$-axis is considered to group the 120 members into seven independent size variables. This is also a benchmark problem that has been previously examined in a variety of studies such as $[7-9,17,25]$.

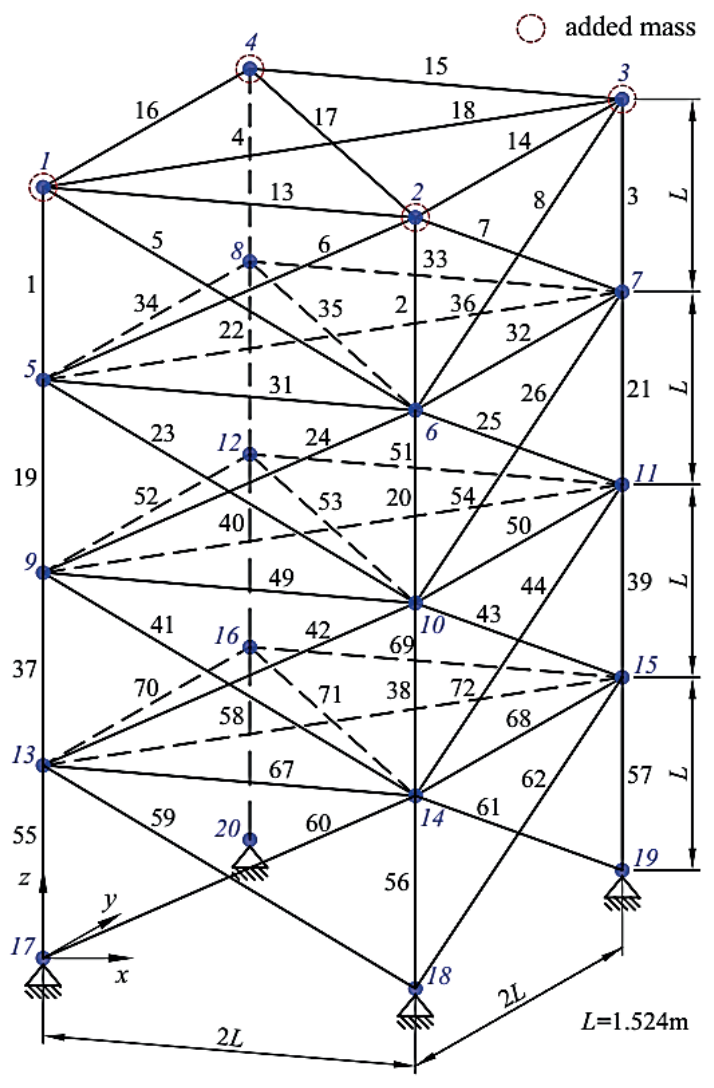

Fig. 4 The 72-bar space truss 


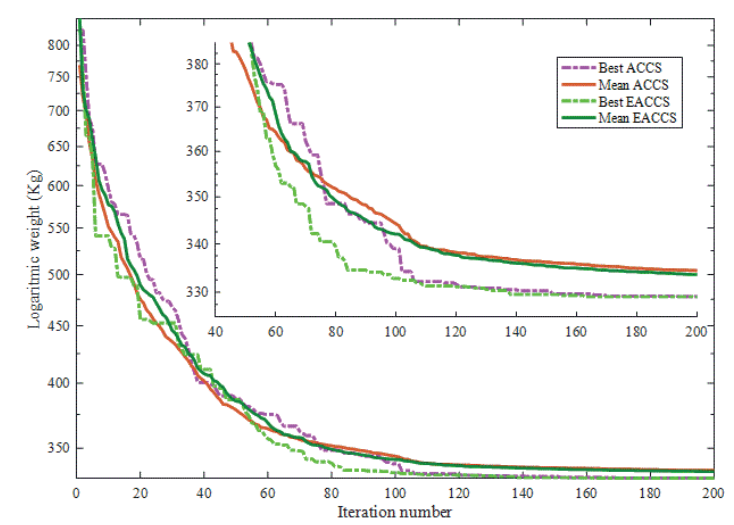

Fig. 5 The weight convergence histories of the 72-bar planar truss obtained using the ACCS and EACCS

Table 6 presents a comparison of the optimal results obtained by this work with those available in the literature. It can be noticed that in this case, the EACCS has the smallest optimal weight compared to the others. As reveals from the table, the standard deviation of the EACCS is lower than the others. The optimized structural frequencies $(\mathrm{Hz})$ for these methods are presented in Table 7. None of the frequency constraints are violated. Fig. 7 shows the weight convergence histories obtained using both ACCS and EACCS algorithms for this problem.
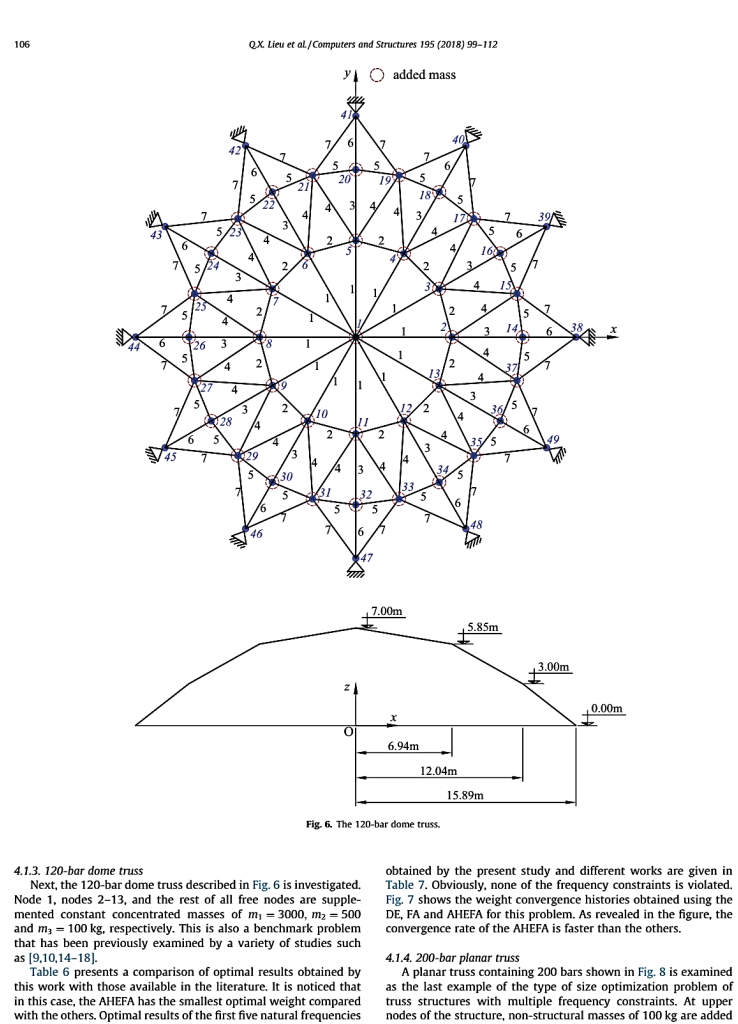

Fig. 6 The 120-bar dome truss

Table 5 Natural frequencies (Hz) of the optimized designs for the 72-bar planar truss

\begin{tabular}{|c|c|c|c|c|c|c|c|}
\hline \multirow{2}{*}{ Frequency No. } & \multirow{2}{*}{ PSO [5] } & \multirow{2}{*}{ HS [10] } & \multirow{2}{*}{ CSS [8] } & \multirow{2}{*}{ FA [10] } & \multirow{2}{*}{ CPA [6] } & \multicolumn{2}{|c|}{ This work } \\
\hline & & & & & & $\mathrm{ACCS}$ & EACCS \\
\hline 1 & 4.000 & 4.0000 & 4.000 & 4.000 & 4.000 & 4.0000 & 4.0000 \\
\hline 2 & 4.000 & 4.0000 & 4.000 & 4.000 & 4.000 & 4.0000 & 4.0000 \\
\hline 3 & 6.000 & 6.0000 & 6.006 & 6.000 & 6.000 & 6.0112 & 6.0007 \\
\hline 4 & 6.219 & 6.2723 & 6.210 & 6.247 & 6.238 & 7.6655 & 6.4325 \\
\hline 5 & 8.976 & 9.0749 & 8.684 & 9.038 & 9.035 & 9.7585 & 9.1635 \\
\hline
\end{tabular}

Table 6 Comparison of optimal results of the 120-bar dome truss obtained by different algorithms

\begin{tabular}{|c|c|c|c|c|c|c|c|}
\hline \multirow{2}{*}{$\begin{array}{l}\text { Design variable } \\
A_{i}\left(\mathrm{~cm}^{2}\right)\end{array}$} & \multirow{2}{*}{ CSS [8] } & \multirow{2}{*}{ CBO [26] } & \multirow{2}{*}{ PSO [7] } & \multirow{2}{*}{ VPS [13] } & \multirow{2}{*}{ SOS [17] } & \multicolumn{2}{|c|}{ This work } \\
\hline & & & & & & ACCS & EACCS \\
\hline $\mathrm{A}_{1}$ & 21.710 & 19.6917 & 23.494 & 19.6836 & 19.5203 & 19.3331 & 19.5342 \\
\hline $\mathrm{A}_{2}$ & 40.862 & 41.1421 & 32.976 & 40.9581 & 40.8482 & 40.9855 & 40.3209 \\
\hline $\mathrm{A}_{3}$ & 09.048 & 11.1550 & 11.492 & 11.3325 & 10.3225 & 10.4487 & 10.5741 \\
\hline $\mathrm{A}_{4}$ & 19.673 & 21.3207 & 24.839 & 21.5387 & 20.9277 & 20.9748 & 21.0753 \\
\hline $\mathrm{A}_{5}$ & 08.336 & 09.8330 & 09.964 & 09.8867 & 09.6554 & 9.80400 & 09.7126 \\
\hline $\mathrm{A}_{6}$ & 16.120 & 12.8520 & 12.039 & 12.7116 & 12.1127 & 12.0105 & 11.7997 \\
\hline $\mathrm{A}_{7}$ & 18.976 & 15.1602 & 14.249 & 14.9330 & 15.0313 & 14.8797 & 14.9179 \\
\hline Best weight (kg) & 9204.510 & 8889.1303 & 9171.93 & 8888.74 & 8713.3030 & 8704.7655 & 8703.7014 \\
\hline Average weight (kg) & - & 8891.2540 & 9251.84 & 8896.04 & 8735.3452 & 8728.0188 & 8704.4643 \\
\hline Standard deviation & - & 1.7926 & 89.380 & 6.650 & 17.9011 & 12.2037 & 0.7839 \\
\hline No. of analyses & 4,000 & 6,000 & 6,000 & 30,000 & 4,000 & 8,000 & 6,000 \\
\hline
\end{tabular}


Table 7 Natural frequencies $(\mathrm{Hz})$ of the optimized designs for the 120-bar planar truss

\begin{tabular}{lccccccc}
\hline Frequency No. & CSS [8] & CBO [26] & PSO [7] & VPS [13] & SOS [17] & \multicolumn{2}{c}{ This work } \\
\hline 1 & & & & & ACCS & EACCS \\
2 & 09.002 & 09.0000 & 09.0000 & 09.0000 & 09.0009 & 09.0000 & 09.0000 \\
3 & 11.002 & 11.0000 & 11.0000 & 11.0000 & 11.0005 & 11.0000 & 11.0000 \\
4 & 11.006 & 11.0000 & 11.0052 & 11.0000 & 11.0005 & 11.0026 & 11.0027 \\
5 & 11.015 & 11.0096 & 11.0134 & 11.0096 & 11.0046 & 11.0112 & 11.0113 \\
\hline
\end{tabular}

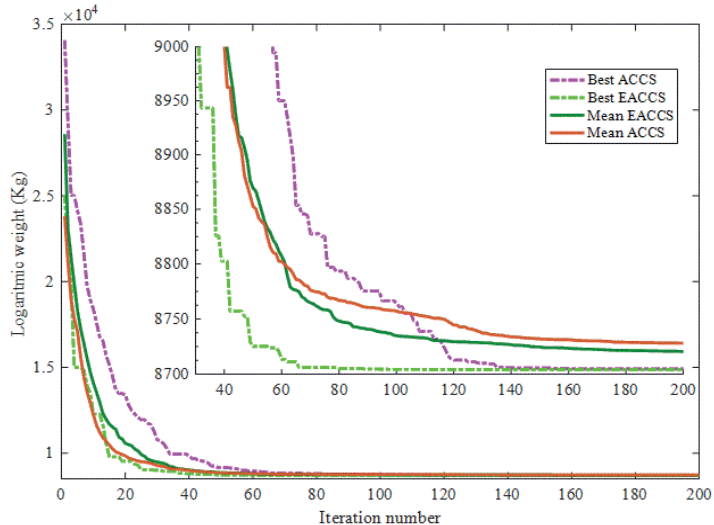

Fig. 7 The weight convergence histories of the 120-bar planar truss obtained using the ACCS and EACCS

\subsubsection{The 200-bar planar truss}

A planar truss containing 200 bars, shown in Fig. 8, is optimized as the last example of the type of size optimization problem of truss structures with multiple frequency constraints. At upper nodes of the structure, non-structural masses of $100 \mathrm{~kg}$ are added for the free vibration analysis. Members of the structure are categorized into 29 groups corresponding to 29 design variables as indicated in Table 8 . This example has formerly been considered in detail by numerous researchers with different methods [6-9].

Similar to the previously illustrated examples, optimal results obtained by the present algorithms and different approaches are summarized in Table 8 for comparison. As it can be seen, the best and average weight and standard deviation corresponding to the EACCS are better than some of the other methods. Furthermore, the number of $\mathrm{FE}$ analyses used to gain the optimal weight is the least for the EACCS.

Optimal natural frequencies obtained by different algorithms are displayed in Table 9. It can be recognized that none of the constraints are violated. The weight convergence histories obtained using both algorithms for this structure are shown in Fig. 9. Clearly, the convergence rate of the EACCS is always better than the other algorithms.

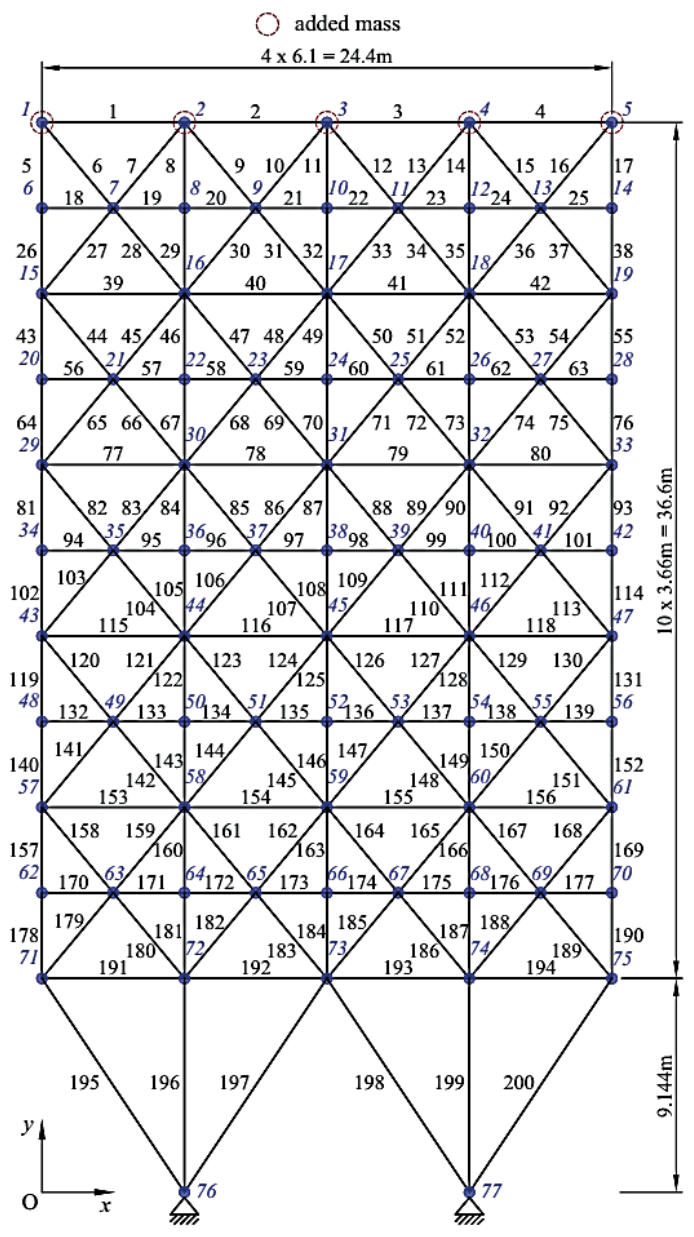

Fig. 8 The 200-bar planar truss

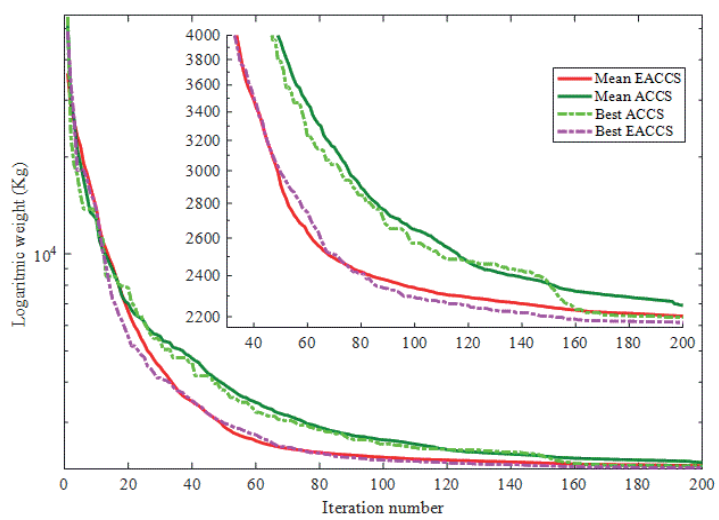

Fig. 9 The weight convergence histories of the 200-bar planar truss obtained using the ACCS and EACCS 
Table 8 Optimal cross-sectional areas for the 200-bar planar truss $\left(\mathrm{cm}^{2}\right)$

\begin{tabular}{|c|c|c|c|c|c|c|}
\hline \multicolumn{2}{|r|}{ Design variable } & \multirow{2}{*}{ CSS [8] } & \multirow{2}{*}{$\begin{array}{c}\text { TLBO } \\
{[28]}\end{array}$} & \multirow{2}{*}{ SOS [17] } & \multicolumn{2}{|c|}{ This work } \\
\hline $\mathrm{Ai}\left(\mathrm{cm}^{2}\right)$ & Member group & & & & ACCS & EACCS \\
\hline 1 & $1,2,3,4$ & 0.2439 & 0.3030 & 0.4781 & 0.3262 & 0.3175 \\
\hline 2 & $5,8,11,14,17$ & 0.1438 & 0.4479 & 0.4481 & 0.406 & 0.4452 \\
\hline 3 & $19,20,21,22,23,24$ & 0.3769 & 0.1001 & 0.1049 & 0.1062 & 0.1004 \\
\hline 4 & $18,25,56,63,94,101,132,139,170,177$ & 0.1494 & 0.1000 & 0.1045 & 0.1082 & 0.1004 \\
\hline 5 & $26,29,32,35,38$ & 0.4835 & 0.5124 & 0.4875 & 0.4917 & 0.4964 \\
\hline 6 & $6,7,9,10,12,13,15,16,27,28,30,31,33,34,36,37$ & 0.8103 & 0.8205 & 0.9353 & 0.8509 & 0.8226 \\
\hline 7 & $39,40,41,42$ & 0.4364 & 0.1000 & 0.1200 & 0.1024 & 0.1095 \\
\hline 8 & $43,46,49,52,55$ & 1.4554 & 1.4499 & 1.3236 & 1.4816 & 1.3878 \\
\hline 9 & $57,58,59,60,61,62$ & 1.0103 & 0.1001 & 0.1015 & 0.1318 & 0.1006 \\
\hline 10 & $64,67,70,73,76$ & 2.1382 & 1.5955 & 1.4827 & 1.6093 & 1.5465 \\
\hline 11 & $44,45,47,48,50,51,53,54,65,66,68,69,71,72,74,75$ & 0.8583 & 1.1556 & 1.1384 & 1.1354 & 1.1541 \\
\hline 12 & $77,78,79,80$ & 1.2718 & 0.1242 & 0.1020 & 0.1196 & 0.1592 \\
\hline 13 & $81,84,87,90,93$ & 3.0807 & 2.9753 & 2.9943 & 3.0434 & 2.9979 \\
\hline 14 & $95,96,97,98,99,100$ & 0.2677 & 0.1000 & 0.1562 & 0.3132 & 0.1007 \\
\hline 15 & $102,105,108,111,114$ & 4.2403 & 3.2553 & 3.4330 & 3.2862 & 3.2726 \\
\hline 16 & $82,83,85,86,88,89,91,92,103,104,106,107,109,110,112,113$ & 2.0098 & 1.5762 & 1.6816 & 1.5869 & 1.5753 \\
\hline 17 & $115,116,117,118$ & 1.5956 & 0.2680 & 0.1026 & 0.2249 & 0.2768 \\
\hline 18 & $119,122,125,128,131$ & 6.2338 & 5.0692 & 5.0739 & 5.085 & 5.0434 \\
\hline 19 & $133,134,135,136,137,138$ & 2.5793 & 0.1000 & 0.1068 & 0.1709 & 0.1076 \\
\hline 20 & $140,143,146,149,152$ & 3.0520 & 5.4281 & 6.0176 & 5.2071 & 5.449 \\
\hline 21 & $120,121,123,124,126,127,129,130,141,142,144,145,147,148,150,151$ & 1.8121 & 2.0942 & 2.0340 & 2.2289 & 2.1447 \\
\hline 22 & $153,154,155,156$ & 1.2986 & 0.6985 & 0.6595 & 0.2708 & 0.6745 \\
\hline 23 & $157,160,163,166,169$ & 5.8810 & 7.6663 & 6.9003 & 8.027 & 7.6967 \\
\hline 24 & $171,172,173,174,175,176$ & 0.2324 & 0.1008 & 0.2020 & 0.2105 & 0.1353 \\
\hline 25 & $178,181,184,187,190$ & 7.7536 & 7.9899 & 6.8356 & 7.8354 & 7.7106 \\
\hline 26 & $158,159,161,162,164,165,167,168,179,180,182,183,185,186,188,189$ & 2.6871 & 2.8084 & 2.6644 & 2.9012 & 2.7915 \\
\hline 27 & $191,192,193,194$ & 12.5094 & 10.4661 & 12.1430 & 9.5438 & 10.3755 \\
\hline 28 & $195,197,198,200$ & 29.5704 & 21.2466 & 22.2484 & 21.438 & 21.3364 \\
\hline 29 & 196,199 & 8.2910 & 10.7340 & 8.9378 & 11.307 & 10.7345 \\
\hline Best weig & ht $(\mathrm{kg})$ & 2259.86 & 2156.541 & 2180.3210 & 2167.4954 & 2156.3651 \\
\hline Average & weight (kg) & - & 2157.547 & 2303.3034 & 2180.3886 & 2157.6554 \\
\hline Standard & deviation & - & 1.545 & 83.5897 & 8.1411 & 1.7683 \\
\hline No. of an & alyses & 10,000 & 23,000 & 10,000 & 23,000 & 23,000 \\
\hline
\end{tabular}

Table 9 Natural frequencies $(\mathrm{Hz})$ of the optimized designs for the 200-bar planar truss

\begin{tabular}{|c|c|c|c|c|c|}
\hline \multirow{2}{*}{ Frequency No. } & \multirow{2}{*}{ CSS [8] } & \multirow{2}{*}{ TLBO [28] } & \multirow{2}{*}{ SOS [17] } & \multicolumn{2}{|c|}{ This work } \\
\hline & & & & ACCS & EACCS \\
\hline 1 & 5.010 & 5.00000 & 5.0001 & 5.0000 & 5.0000 \\
\hline 2 & 12.911 & 12.21710 & 13.4306 & 12.3550 & 12.3137 \\
\hline 3 & 15.416 & 15.03796 & 15.2645 & 15.0212 & 15.0226 \\
\hline 4 & 17.033 & 16.70476 & - & 16.8172 & 16.6997 \\
\hline 5 & 21.426 & 21.40164 & - & 21.4369 & 21.4152 \\
\hline 6 & 21.613 & 21.45347 & - & 21.7894 & 21.6432 \\
\hline
\end{tabular}




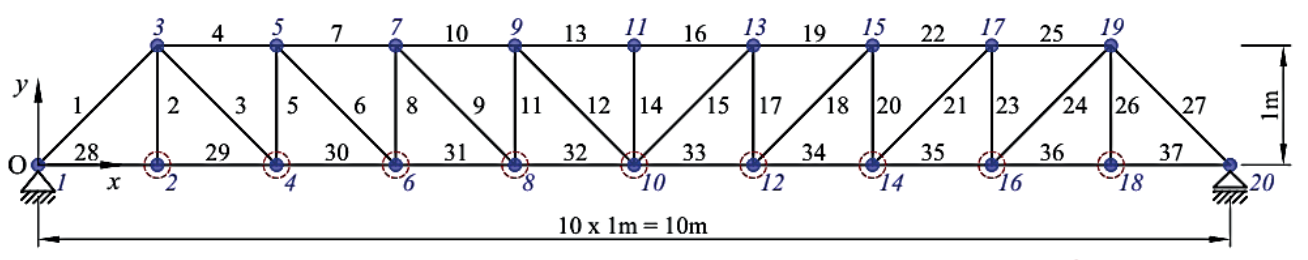

( added mass

Fig. 10 The initial shape of the 37-bar planar truss

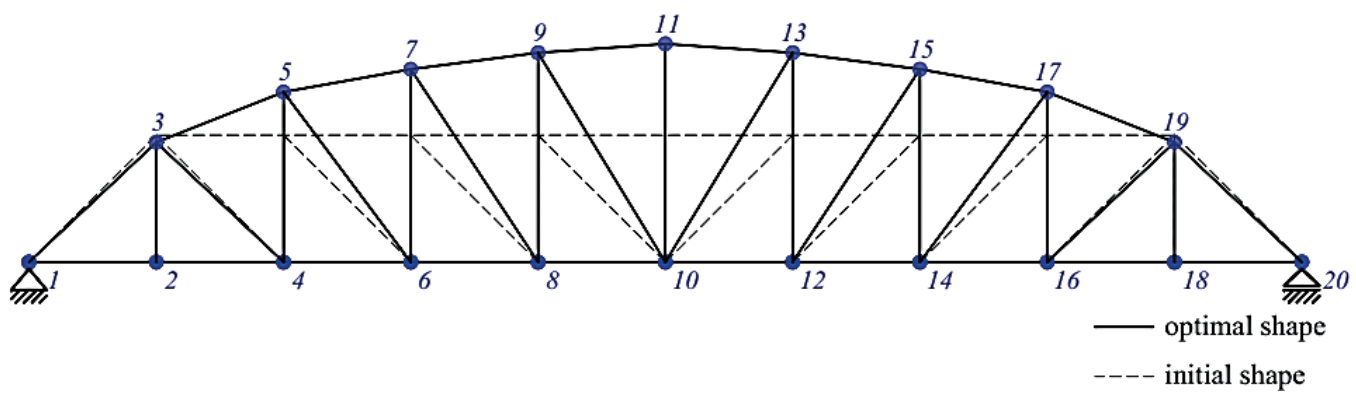

Fig. 11 Final configuration found by the artificial coronary circulation system algorithm for the simply supported planar 37-bar truss

Table 10 Comparison of optimal results of the 37-bar planar truss obtained by different algorithms

\begin{tabular}{|c|c|c|c|c|c|c|c|}
\hline \multirow{2}{*}{$\begin{array}{l}\text { Design variable } \\
\mathrm{Y}_{\mathrm{j}}(\mathrm{m}) ; \mathrm{A}_{\mathrm{i}}\left(\mathrm{cm}^{2}\right)\end{array}$} & \multirow{2}{*}{ Initial } & \multirow{2}{*}{ PSO [5] } & \multirow{2}{*}{ HS [10] } & \multirow{2}{*}{ CSS [8] } & \multirow{2}{*}{ SOS [17] } & \multicolumn{2}{|c|}{ This work } \\
\hline & & & & & & ACCS & EACCS \\
\hline Y3; Y19 & 1.0000 & 0.9637 & 0.8415 & 0.8726 & 0.9598 & 0.9958 & 0.9352 \\
\hline Y5; Y17 & 1.0000 & 1.3978 & 1.2409 & 1.2129 & 1.3867 & 1.405 & 1.3114 \\
\hline Y7; Y15 & 1.0000 & 1.5929 & 1.4464 & 1.3826 & 1.5698 & 1.5976 & 1.4983 \\
\hline Y9; Y13 & 1.0000 & 1.8812 & 1.5334 & 1.4706 & 1.6687 & 1.7117 & 1.6284 \\
\hline Y11 & 1.0000 & 2.0856 & 1.5971 & 1.5683 & 1.7203 & 1.818 & 1.7064 \\
\hline $\mathrm{A} 1 ; \mathrm{A} 27$ & 1.0000 & 2.6797 & 3.2031 & 2.9082 & 2.9038 & 2.8671 & 2.9045 \\
\hline A2; A26 & 1.0000 & 1.1568 & 1.1107 & 1.0212 & 1.0163 & 1.0717 & 1.0013 \\
\hline A3; A24 & 1.0000 & 2.3476 & 1.1871 & 1.0363 & 1.0033 & 1.0035 & 1.0156 \\
\hline A4; A25 & 1.0000 & 1.7182 & 3.3281 & 3.9147 & 3.1940 & 2.2862 & 2.6157 \\
\hline A5; A23 & 1.0000 & 1.2751 & 1.4057 & 1.0025 & 1.0109 & 1.3468 & 1.1372 \\
\hline A6; A21 & 1.0000 & 1.4819 & 1.0883 & 1.2167 & 1.5877 & 1.1864 & 1.2058 \\
\hline A7; A22 & 1.0000 & 4.6850 & 2.1881 & 2.7146 & 2.4104 & 2.415 & 2.5863 \\
\hline A8; A20 & 1.0000 & 1.1246 & 1.2223 & 1.2663 & 1.3864 & 1.5053 & 1.3730 \\
\hline A9; A18 & 1.0000 & 2.1214 & 1.7033 & 1.8006 & 1.6276 & 1.3932 & 1.4763 \\
\hline A10; A19 & 1.0000 & 3.8600 & 3.1885 & 4.0274 & 2.3594 & 2.0878 & 2.4519 \\
\hline A11; A17 & 1.0000 & 2.9817 & 1.0100 & 1.3364 & 1.0293 & 1.3208 & 1.2508 \\
\hline A12; A15 & 1.0000 & 1.2021 & 1.4074 & 1.0548 & 1.3721 & 1.2846 & 1.3155 \\
\hline A13; A16 & 1.0000 & 1.2563 & 2.8499 & 2.8116 & 2.0673 & 2.2003 & 2.2816 \\
\hline A14 & 1.0000 & 3.3276 & 1.0269 & 1.1702 & 1.0000 & 1.0286 & 1.0003 \\
\hline Best weight (kg) & 336.30 & 377.20 & 361.50 & 362.84 & 360.8658 & 359.5543 & 358.9324 \\
\hline Average weight (kg) & - & 381.20 & 362.04 & 366.77 & 364.8521 & 361.6809 & 359.0855 \\
\hline Standard deviation & - & 4.26 & 0.52 & 3.742 & 2.9650 & 1.7354 & 0.1246 \\
\hline No. of FE analyses & - & - & 20,000 & - & 4,000 & 8,000 & 8,000 \\
\hline
\end{tabular}


Table 11 The optimal natural frequencies of the 37-bar planar truss obtained by different algorithms

\begin{tabular}{|c|c|c|c|c|c|c|c|}
\hline \multirow{2}{*}{ Frequency No. } & \multirow{2}{*}{ Initial } & \multirow{2}{*}{ PSO [5] } & \multirow{2}{*}{ HS [10] } & \multirow{2}{*}{ CSS [8] } & \multirow{2}{*}{ SOS [17] } & \multicolumn{2}{|c|}{ This work } \\
\hline & & & & & & ACCS & EACCS \\
\hline 1 & 8.89 & 20.0001 & 20.0037 & 20.0000 & 20.0366 & 20.0084 & 20.0003 \\
\hline 2 & 28.82 & 40.0003 & 40.0050 & 40.0693 & 40.0007 & 40.0280 & 40.0058 \\
\hline 3 & 46.92 & 60.0001 & 60.0082 & 60.6982 & 60.0138 & 60.0397 & 60.0049 \\
\hline 4 & 63.62 & 73.0440 & 77.9753 & 75.7339 & - & 76.8668 & 76.4605 \\
\hline 5 & 76.87 & 89.8240 & 96.2564 & 97.6137 & - & 96.7594 & 96.6879 \\
\hline
\end{tabular}

Table 12 Comparison of optimal results of the 52-bar dome truss obtained by different algorithms

\begin{tabular}{|c|c|c|c|c|c|c|c|c|}
\hline \multirow{2}{*}{$\begin{array}{l}\text { Design variable } \\
\mathrm{Z}_{\mathrm{j}}, \mathrm{X}_{\mathrm{j}}(\mathrm{m}) ; \mathrm{A}_{\mathrm{i}}\left(\mathrm{cm}^{2}\right)\end{array}$} & \multirow{2}{*}{ Initial } & \multirow{2}{*}{ GA [22] } & \multirow{2}{*}{ PSO [5] } & \multirow{2}{*}{ HS [10] } & \multirow{2}{*}{ CSS [9] } & \multirow{2}{*}{$\mathrm{CBO}[25]$} & \multicolumn{2}{|c|}{ This work } \\
\hline & & & & & & & ACCS & EACCS \\
\hline $\mathrm{Z}_{\mathrm{A}}$ & 6.0 & 5.8851 & 5.5344 & 4.7374 & 5.2716 & 5.6523 & 6.0230 & 6.1496 \\
\hline $\mathrm{X}_{\mathrm{B}}$ & 2.0 & 1.7623 & 2.0885 & 1.5643 & 1.5909 & 1.9665 & 2.1831 & 2.2497 \\
\hline$Z_{\text {B }}$ & 5.7 & 4.4091 & 3.9283 & 3.7413 & 3.7039 & 3.7378 & 3.8056 & 3.8670 \\
\hline $\mathrm{X}_{\mathrm{F}}$ & 4.0 & 3.4406 & 4.0255 & 3.4882 & 3.5595 & 3.7620 & 4.0401 & 4.1004 \\
\hline$Z_{F}$ & 4.5 & 3.1874 & 2.4575 & 2.6274 & 2.5757 & 2.5741 & 2.5015 & 2.5002 \\
\hline $\mathrm{A}_{1}$ & 2.0 & 1.0000 & 0.3696 & 1.0085 & 1.0464 & 1.0009 & 1.0037 & 1.0002 \\
\hline $\mathrm{A}_{2}$ & 2.0 & 2.1417 & 4.1912 & 1.4999 & 1.7295 & 1.3326 & 1.1422 & 1.1116 \\
\hline $\mathrm{A}_{3}$ & 2.0 & 1.4858 & 1.5123 & 1.3948 & 1.6507 & 1.3751 & 1.3115 & 1.2031 \\
\hline $\mathrm{A}_{4}$ & 2.0 & 1.4018 & 1.5620 & 1.3462 & 1.5059 & 1.6327 & 1.3726 & 1.2816 \\
\hline $\mathrm{A}_{5}$ & 2.0 & 1.911 & 1.9154 & 1.6776 & 1.7210 & 1.5521 & 1.3898 & 1.3620 \\
\hline $\mathrm{A}_{6}$ & 2.0 & 1.0109 & 1.1315 & 1.3704 & 1.0020 & 1.0000 & 1.3883 & 1.3462 \\
\hline $\mathrm{A}_{7}$ & 2.0 & 1.4693 & 1.8233 & 1.4137 & 1.7415 & 1.6071 & 1.3165 & 1.2910 \\
\hline $\mathrm{A}_{8}$ & 2.0 & 2.1411 & 1.0904 & 1.9378 & 1.2555 & 1.3354 & 1.5172 & 1.6409 \\
\hline Best weight (kg) & 338.69 & 236.046 & 228.381 & 214.94 & 205.237 & 197.962 & 199.2701 & 198.8307 \\
\hline Average weight (kg) & - & - & 234.30 & 229.88 & 213.101 & 206.858 & 206.2003 & 199.6934 \\
\hline Standard deviation & - & - & 5.22 & 12.44 & 7.391 & 5.750 & 6.5425 & 1.9257 \\
\hline No. of analyses & - & - & - & 20,000 & 4,000 & 4,000 & 8,000 & 8,000 \\
\hline
\end{tabular}

Table 13 The optimal natural frequencies of the 52-bar dome truss obtained by different algorithms

\begin{tabular}{|c|c|c|c|c|c|c|c|c|}
\hline \multirow{2}{*}{ Frequency No. } & \multirow{2}{*}{ Initial } & \multirow{2}{*}{ GA [22] } & \multirow{2}{*}{ PSO [5] } & \multirow{2}{*}{ HS [10] } & \multirow{2}{*}{ CSS [9] } & \multirow{2}{*}{ CBO [25] } & \multicolumn{2}{|c|}{ This work } \\
\hline & & & & & & & ACCS & EACCS \\
\hline 1 & 22.69 & 12.81 & 12.751 & 12.2222 & 9.246 & 10.2404 & 11.3007 & 11.7189 \\
\hline 2 & 25.17 & 28.65 & 28.649 & 28.6577 & 28.648 & 28.6482 & 28.6481 & 28.6477 \\
\hline 3 & 25.17 & 28.65 & 28.649 & 28.6577 & 28.699 & 28.6504 & 28.6538 & 28.6486 \\
\hline 4 & 31.52 & 29.54 & 28.803 & 28.6618 & 28.735 & 28.7117 & 28.6594 & 28.6548 \\
\hline 5 & 33.80 & 30.24 & 29.230 & 30.0997 & 29.223 & 29.2045 & 28.7886 & 28.8702 \\
\hline
\end{tabular}

\subsection{Shape and size optimization}

\subsubsection{The 37-bar planar truss}

A simply supported 37-bar planar truss is studied as the shape and size optimization example to demonstrate the effectiveness and robustness of the EACCS. Fig. 10 shows the initial shape and a finite element model of this structure. A constant lumped mass of $10 \mathrm{~kg}$ is placed on each free node of the lower chord, and is assumed to be unchanged during the design process. All bars of the lower chord are fixedly assigned to a constant cross-sectional area of $4 \times 10^{-3} \mathrm{~m}^{2}$, whereas the others possess an initial cross-sectional area of $1 \times 10^{-4} \mathrm{~m}^{2}$. It should be noted that all the nodes of the upper chord are permitted to move vertically, their $y$-axis coordinates are thus taken as design variables. Furthermore, nodal coordinates and member areas are connected so that the structure is symmetric. Consequently, nineteen design variables containing five nodal coordinate and fourteen cross-sectional areas are redesigned. This structure which is a well-known benchmark problem has been previously studied by many researchers [4, 5, 10, 17, 22, 24-26]. 


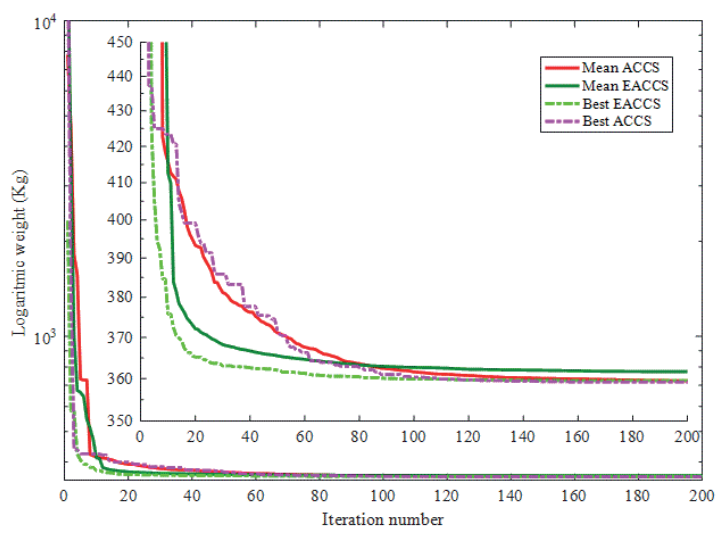

Fig. 12 The weight convergence histories of the 37-bar planar truss obtained using the ACCS and EACCS
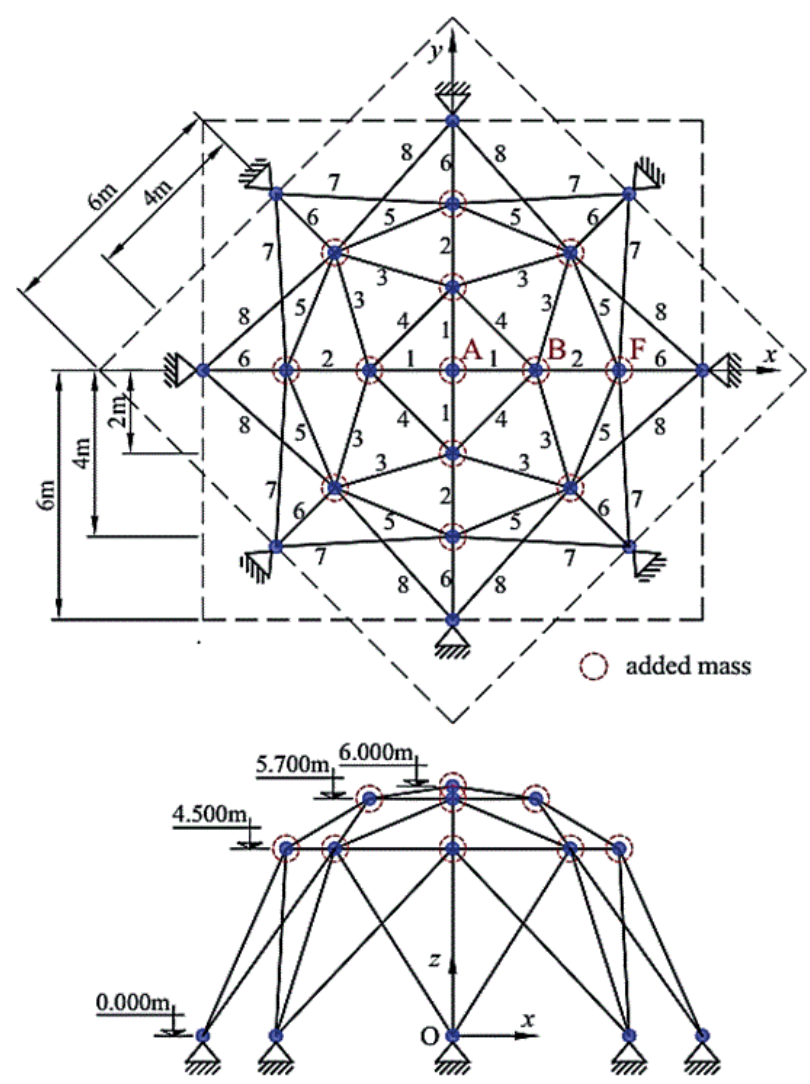

Fig. 13 The initial shape of the 52-bar dome truss

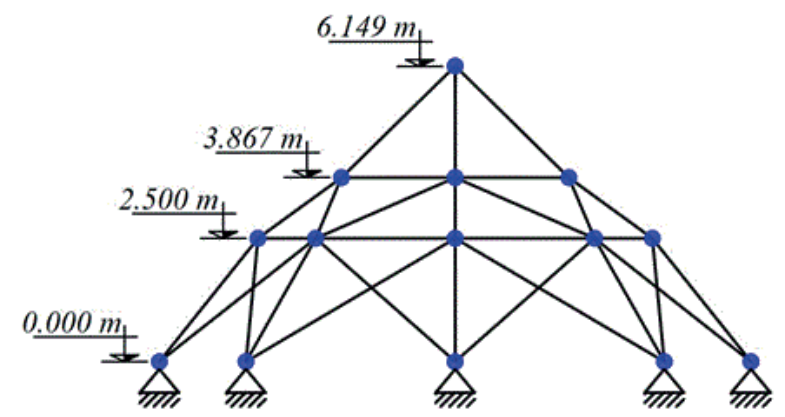

Fig. 14 Final configuration found by the artificial coronary circulation system for the spatial 52-bar truss

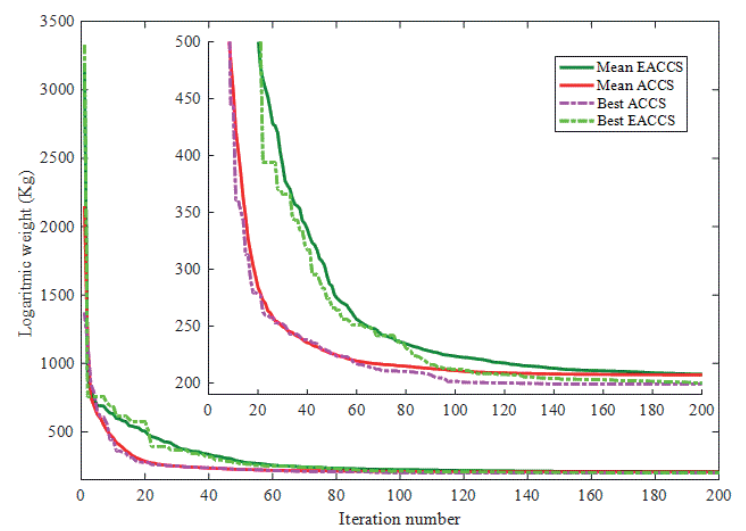

Fig. 15 The weight convergence histories of the 52-bar dome truss

Optimal results obtained by both algorithms and different approaches including cross-sectional areas, nodal coordinates, corresponding weights and statistics results are provided in Table 10. It can be seen that the EACCS results in better solutions than the others.

Table 11 represents the first five optimal natural frequencies attained by the present study and different algorithms. As can be observed, all the optimized frequencies are free from any violations of constraints. Fig. 11 describes the optimal shape of the truss structure obtained using the EACCS. It can be stated that this final shape is quite similar to those obtained in the previously published works. Finally, the convergence rate of the ACCS and EACCS are illustrated in Fig. 12.

\subsubsection{The 52-bar dome truss}

The last example for the shape and size optimization problem is considered as a 52-bar dome truss. The initial schematic of the structure is depicted in Fig. 13. For optimization purpose, the members of the structure are divided into eight variable groups as labeled in the same figure. With each free node a mass of $50 \mathrm{~kg}$ is assigned. The three coordinates $(\mathrm{x}, \mathrm{y}, \mathrm{z})$ of each free node can shift within the range $\pm 2 \mathrm{~m}$, and these are also considered as design variables. It should be noted that the entire structure must preserve its symmetry during the optimization process. Thus, there are thirteen independent design variables consisting of five shape and eight size variables. All member areas are initially assigned a value of $2 \times 10^{-4} \mathrm{~m}^{2}$. This dome truss is a well-known benchmark problem has previously been studied by researchers such as [5-10, 17, 24, 27].

Table 12 contains a comparison of the optimal results obtained by both ACCS and EACCS algorithms, and the other considered approaches. The effectiveness and robustness of the EACCS, the optimal weight achieved by 
the proposed method is the best compared to those given by the other considered algorithms as indicated in the table. Table 13 displays the first five optimal natural frequencies for different optimization methods. It can easily be seen that no violation of constraints are present for the optimized results. Fig. 14 sketches the final optimal shape of the structure given by the EACCS after the design process. It should be noted that similar configurations were also found by various studies in the literature. Fig. 15 shows the weight convergence histories obtained using the EACCS for this structure.

\section{Conclusions}

In this paper, a new enhanced ACCS is proposed for dealing with shape and size optimization problems of truss structures under multiple frequency constraints. The present algorithm is a bio-inspired population-based metaheuristic based on the re-growing behavior of the capillaries and arteries, which can happen repeatedly. Six numerical benchmark examples with highly nonlinear and non-convex properties including four examples for size optimization and two examples for shape and size optimization are tested to verify the effectiveness and robustness of the proposed approach.

The results are compared with those of some other optimization algorithms on the same problems. The results indicate that the performance of the EACCS is comparable to the other state-of-the-art methods. In fact, for six of the examples, EACCS found the best results among the compared methods.

Therefore, the EACCS is very promising algorithm to extend its applications to various engineering optimization problems in many fields with the high feasibility where the computational cost is important. Also, the EACCS is a multi-purpose optimization algorithm which can be used for other types of optimization problems from different fields of science and engineering. Application of the EACCS to different classes of optimization problems, and investigation of possible variants and modifications, could be the subject of future studies. Form the results of this study it can be concluded that both standard ACCS and its enhanced version have performed better than the many other methods available in the literature in some of the examples considered, and in one example the design is only slightly heavier than the best one found.

\section{References}

[1] Pholdee, N., Bureerat, S. "Comparative performance of meta-heuristic algorithms for mass minimisation of trusses with dynamic constraints", Advances in Engineering Software, 75, pp. 1-13, 2014. https://doi.org/10.1016/j.advengsoft.2014.04.005

[2] Tejani, G. G., Savsani, V. J., Patel, V. K., Mirjalili, S. "Truss optimization with natural frequency bounds using improved symbiotic organisms search", Knowledge-Based Systems, 143, pp. 162-178, 2018.

https://doi.org/10.1016/j.knosys.2017.12.012

[3] Grandhi, R. V., Venkayya, V. B. "Structural optimization with frequency constraints", AIAA journal, 26(7), pp. 858-866, 1988. https://doi.org/10.2514/3.9979

[4] Wang, D., Zhang, W. H., Jiang, J. S. "Truss optimization on shape and sizing with frequency constraints", AIAA journal, 42(3), pp. 622-630, 2004.

https://doi.org/10.2514/1.1711

[5] Gomes, H. M. "Truss optimization with dynamic constraints using a particle swarm algorithm", Expert Systems with Applications, 38(1), pp. 957-968, 2011.

https://doi.org/10.1016/j.eswa.2010.07.086

[6] Kaveh, A., Ilchi Ghazaan, M., Bakhshpoori, T. "An improved ray optimization algorithm for design of truss structures", Periodica Polytechnica Civil Engineering, 57(2), pp. 97-112, 2013. https://doi.org/10.3311/PPci.7166

[7] Kaveh, A., Zolghadr, A. "Democratic PSO for truss layout and size optimization with frequency constraints", Computers \& Structures, 130, pp. 10-21, 2014.

https://doi.org/10.1016/j.compstruc.2013.09.002

[8] Kaveh, A., Zolghadr, A. "Truss optimization with natural frequency constraints using a hybridized CSS-BBBC algorithm with trap recognition capability", Computers \& Structures, 102-103, pp. 14-27, 2012.

https://doi.org/10.1016/j.compstruc.2012.03.016

[9] Kaveh, A., Zolghadr, A. "Shape and size optimization of truss structures with frequency constraints using enhanced charged system search algorithm", Asian Journal of Civil Engineering, 12(4), pp. 487-509, 2011. [online] Available at: https://www.sid.ir/en/journal/ ViewPaper.aspx?id=248035 [Accessed: 23 January 2019]

[10] Miguel, L. F. F., Miguel, L. F. F. "Shape and size optimization of truss structures considering dynamic constraints through modern metaheuristic algorithms", Expert Systems with Applications, 39(10), pp. 9458-9467, 2012.

https://doi.org/10.1016/j.eswa.2012.02.113

[11] Savsani, V. J., Tejani, G. G., Patel, V. K. "Truss topology optimization with static and dynamic constraints using modified subpopulation teaching-learning-based optimization", Engineering Optimization, 48(11), pp. 1990-2006, 2016. https://doi.org/10.1080/0305215X.2016.1150468

[12] Kaveh, A., Mahdavi, V. R. "Optimal design of structures with multiple natural frequency constraints using a hybridized BB-BC/QuasiNewton algorithm", Periodica Polytechnica Civil Engineering, 57(1), pp. 27-38, 2013. https://oi.org/10.3311/PPci.2139 
[13] Kaveh, A., Ilchi Ghazaan, M. "Vibrating particles system algorithm for truss optimization with multiple natural frequency constraints", Acta Mechanica, 228(1), pp. 307-322, 2017. https://doi.org/10.1007/s00707-016-1725-z

[14] Kaveh, A., Ilchi Ghazaan, M. "Enhanced colliding bodies algorithm for truss optimization with frequency constraints", Journal of Computing in Civil Engineering, 29(6), 2015. https://doi.org/10.1061/(ASCE)CP.1943-5487.0000445

[15] Kaveh, A., Zolghadr, A. "Topology optimization of trusses considering static and dynamic constraints using the CSS", Applied Soft Computing, 13(5), pp. 2727-2734, 2013.

https://doi.org/10.1016/j.asoc.2012.11.014

[16] Savsani, V. J., Tejani, G. G., Patel, V. K., Savsani, P. "Modified meta-heuristics using random mutation for truss topology optimization with static and dynamic constraints", Journal of Computational Design and Engineering, 4(2), pp. 106-130, 2017. https://doi.org/10.1016/j.jcde.2016.10.002

[17] Tejani, G. G., Savsani, V. J., Patel, V. K. "Adaptive symbiotic organisms search (SOS) algorithm for structural design optimization", Journal of Computational Design and Engineering, 3(3), pp. 226-249, 2016.

https://doi.org/10.1016/j.jcde.2016.02.003

[18] Maute, K., Frangopol, D. M. "Reliability-based design of MEMS mechanisms by topology optimization", Computers \& Structures, 81(8-11), pp. 813-824, 2003. https://doi.org/10.1016/S0045-7949(03)00008-7

[19] Yildiz, A. R. "A new hybrid particle swarm optimization approach for structural design optimization in the automotive industry", Proceedings of the Institution of Mechanical Engineers, Part D: Journal of Automobile Engineering, 226(10), pp. 1340-1351, 2012. https://doi.org/10.1177\%2F0954407012443636

[20] Yildiz, A. R. "Comparison of evolutionary-based optimization algorithms for structural design optimization", Engineering Applications of Artificial Intelligence, 26(1), pp. 327-333, 2013. https://doi.org/10.1016/j.engappai.2012.05.014

[21] Kooshkbaghi, M., Kaveh, A. "Sizing optimization of truss structures with continuous variables by artificial coronary circulation system algorithm", Iranian Journal of Science and Technology, in press, 2019.

[22] Lingyun, W., Mei, Z., Guangming, W., Guang, M. "Truss optimization on shape and sizing with frequency constraints based on genetic algorithm", Computational Mechanics, 35(5), pp. 361-368, 2005.

https://doi.org/10.1007/s00466-004-0623-8

[23] Zuo, W., Xu, T., Zhang, H., Xu, T. "Fast structural optimization with frequency constraints by genetic algorithm using adaptive eigenvalue reanalysis methods", Structural and Multidisciplinary Optimization, 43(6), pp. 799-810, 2011. https://doi.org/10.1007/s00158-010-0610-y

[24] Wei, L., Tang, T., Xie, X., Shen, W. "Truss optimization on shape and sizing with frequency constraints based on parallel genetic algorithm", Structural and Multidisciplinary Optimization, 43(5), pp. 665-682, 2011.

https://doi.org/10.1007/s00158-010-0600-0
[25] Kaveh, A., Mahdavi, V. R. "Colliding bodies optimization method for optimum design of truss structures with continuous variables", Advances in Engineering Software, 70, pp. 1-12, 2014. https://doi.org/10.1016/j.advengsoft.2014.01.002

[26] Kaveh, A., Mahdavi, V. R. "Colliding-bodies optimization for truss optimization with multiple frequency constraints", Journal of Computing in Civil Engineering, 29(5), 2015. https://doi.org/10.1061/(ASCE)CP.1943-5487.0000402

[27] Lin, J. H., Che, W. Y., Yu, Y. S. "Structural optimization on geometrical configuration and element sizing with statical and dynamical constraints", Computers \& Structures, 15(5), pp. $507-$ $515,1982$. https://doi.org/10.1016/0045-7949(82)90002-5

[28] Farshchin, M., Camp, C. V., Maniat, M. "Multi-class teachinglearning-based optimization for truss design with frequency constraints", Engineering Structures, 106, pp. 355-369, 2016. https://doi.org/10.1016/j.engstruct.2015.10.039 